\title{
An appendiceal neoplastic lesion: Case report and implications for colonoscopic screening and surveillance
}

\author{
Hugh J Freeman $M D^{1}$, Douglas L Webber $\mathrm{MD}^{2}$, Adam T Meneghetti MD ${ }^{3}$
}

\begin{abstract}
HJ Freeman, DL Webber, AT Meneghetti. An appendiceal neoplastic lesion: Case report and implications for colonoscopic screening and surveillance. Can J Gastroenterol 2009;23(5):379. 381.

A 65-year-old man with a history of previously resected colonic adenomas had an apparent cecal lesion detected during colonoscopy. The polyp proved to be a tubulovillous adenoma with high-grade dysplasia involving most of the body of the appendix along with the base of the cecum. The appendiceal mucosa is biologically similar to the colonic mucosa, yet remains relatively 'hidden' in screening and surveillance studies, which suggests important implications for evolving detection strategies in the follow-up of patients with a previous colon polyp or cancer resections. Although endoscopic removal of the appendix has been reported, treatment of these localized appendiceal lesions requires a wide surgical excision.
\end{abstract}

Key Words: Appendiceal adenoma; Appendiceal carcinoid; Appendiceal carcinoma; Colonoscopy screening; Colorectal cancer

$\mathrm{N}$ eoplastic lesions of the appendix, first described in 1882 , are still considered rare, particularly adenomas and carcinomas, and preoperative diagnosis is notoriously difficult (1). Even appendiceal carcinoids (ie, neuroendocrine tumours) are uncommon but their increased incidence in Crohn's disease was only first recognized in resected intestine, previously reported in this Journal (2) and later confirmed elsewhere by others (3).

In recent years, many agencies have developed guidelines (4-6) for screening and surveillance colonoscopy if previous colon polyps or colon carcinomas have been detected. Because the appendix and colon have reportedly similar mucosal patterns (7), it has been estimated that appendicular adenocarcinoma may account for approximately $1 \%$ of all colorectal malignancies. As colonoscopy numbers continue to increase as a direct result of screening and surveillance, it is likely that appendiceal lesions with or without involvement of the base of the cecum will be detected more often. Rarely, endoscopic resection of the appendix has been possible (8-10).

The present case resulted in diagnosis and resection of an adenomatous lesion involving the appendix extending into the base of the cecum with high-grade dysplasia and raises some critical issues not fully evaluated in current endoscopic or surgical guidelines.

\section{CASE PRESENTATION}

A 65-year-old asymptomatic man was referred for colonoscopy in 2008 by his family physician because of a single-interval positive fecal occult blood test (from three test specimens). Colonoscopic polypectomies were previously performed in

\section{Lésion néoplasique à l'appendice : Rapport de cas et répercussions sur le dépistage et le suivi coloscopiques}

\begin{abstract}
Une coloscopie a révélé la présence d'une lésion caecale apparente chez un homme de 65 ans qui avait déjà subi une résection d'adénome du côlon. Le polype s'est révélé être un adénome tubulo-villeux, avec dysplasie de haut grade affectant la majeure partie de l'appendice et la base du cæcum. La muqueuse de l'appendice est similaire à celle du côlon sur le plan biologique, mais reste relativement hors de portée lors des tests de dépistage et de suivi, ce qui pourrait avoir un retentissement important sur l'amélioration des stratégies de dépistage et de suivi des patients qui ont subi des exérèses de néoplasies ou de polypes au côlon. Bien que des exérèses endoscopiques de l'appendice aient été pratiquées, le traitement de ces lésions localisées requiert une ablation chirurgicale élargie.
\end{abstract}

1987, 1995, 2001 and 2006. Each colonoscopy was complete to the cecum with good bowel preparation and full visualization. Each polyp removed during each of the four previous colonoscopies was pathologically classified as a tubular adenoma, and the colon was considered clear of polyps after each procedure. There was no familial history of colon polyps, cancer or inflammatory bowel disease. His physical examination was normal, and blood tests including hemoglobin were normal.

Colonoscopy revealed a single $10 \mathrm{~mm}$ to $15 \mathrm{~mm}$ sessile, slightly friable polypoid lesion in the base of the cecum abutting and extending into the appendiceal orifice (Figure 1). Biopsies revealed an adenoma with focal high-grade dysplasia. Computed tomography imaging was reported to show focal thickening in the region of the cecum and appendix. Laparoscopic right hemicolectomy defined a tubulovillous adenoma with focal high-grade dysplasia involving the base of the cecum and appendix, but with mucosal extension to involve more than $50 \%$ of the appendix (Figures 2 and 3 ). Lymph nodes in the resected specimen were benign.

\section{DISCUSSION}

Appendiceal neoplasia is uncommon and usually not diagnosed before surgical intervention. Retrospective histopathological reviews of appendectomy specimens have shown that the most common malignant neoplasms of the appendix are carcinoid tumours followed by adenocarcinomas (1). In addition, as noted in resected intestinal specimens from patients with Crohn's disease, the only neoplastic lesions detected were appendiceal carcinoids (2). However, colon screening performed

${ }^{1}$ Department of Gastroenterology; ${ }^{2}$ Department of Pathology; ${ }^{3}$ Department of Surgery, University of British Columbia, Vancouver, British Columbia Correspondence: Dr Hugh J Freeman, Department of Gastroenterology, University of British Columbia Hospital, 2211 Wesbrook Mall,

Vancouver, British Columbia V6T 1W5. Telephone 604-822-7216, fax 604-822-7236, e-mail hugfree@shaw.ca

Received for publication May 17, 2008. Accepted May 19, 2008 


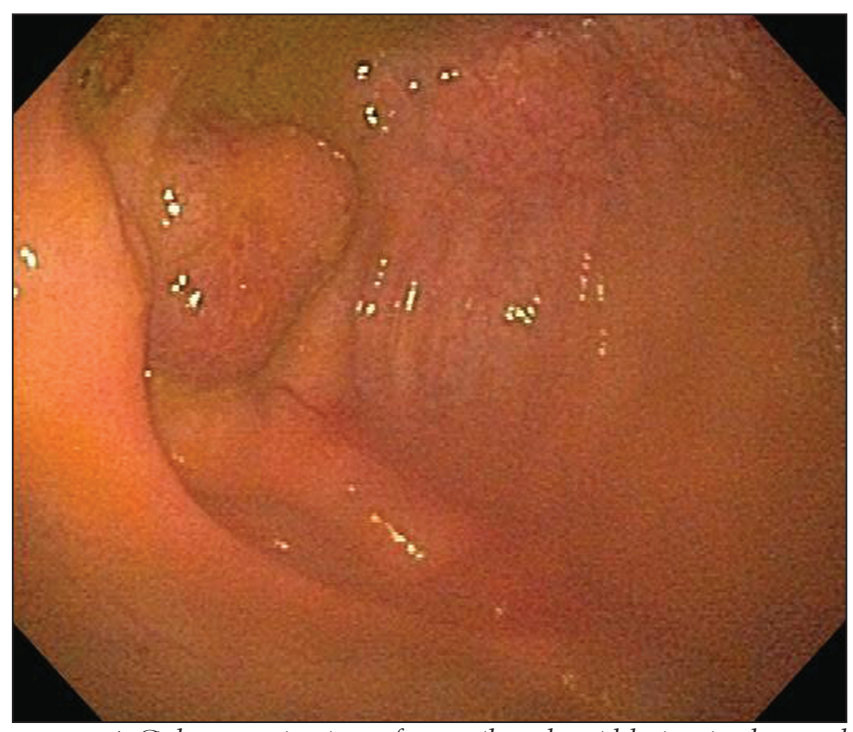

Figure 1) Colonoscopic view of a sessile polypoid lesion in the cecal base adjacent to and extending into the appendiceal orifice. Ileal orifice in foreground

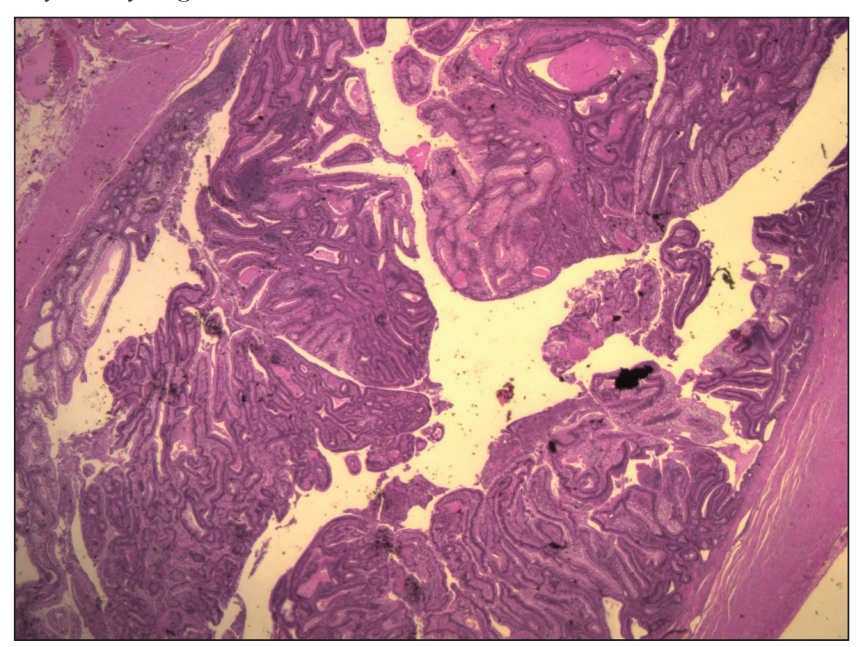

Figure 2) Tubulovillous adenoma in the body of the appendix (hematoxylin and eosin stain, original magnification $\times 12.5$ )

because of a history of previous colon polyps or cancer represents a distinctly different clinical setting and may yield a higher rate of appendiceal neoplasms than these earlier surgical or pathological series have reported.

Indeed, risk of a neoplastic epithelial change in the appendix is likely to be similar to the colon because the biological characteristics of appendiceal and colon epithelia are also similar. Moreover, the heterogeneous nature of colonic adenomas (eg, sessile serrated adenoma) and their possible impact on future screening guidelines (11), is paralleled by reports of serrated neoplasms in the appendix (12). Moreover, recent studies using MLH-1, MSH-2, MGMT, beta-catenin, p53 and Ki-67 expression, BRAF and K-RAS mutations as well as microsatellite instability have also documented molecular features of this 'serrated neoplastic pathway' in appendiceal neoplasms (13). As colonoscopic guidelines for higher risk patients evolve, recognizing the risk of malignant neoplasms in the appendix may become more important than is currently appreciated.

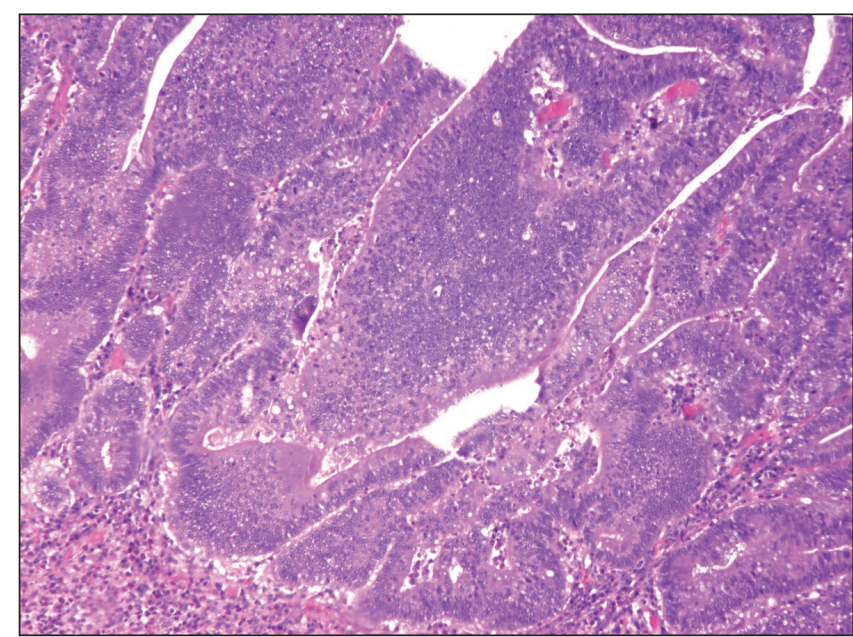

Figure 3) Focus of high-grade dysplasia in appendiceal tubulovillous adenoma (hematoxylin and eosin stain, original magnification $\times 100$ )

Colonoscopic features of neoplastic lesions of the appendix have been described but are not specific. In particular, macroscopic cecal changes have been noted, including secreted mucin in the appendiceal orifice (14). Although endoscopic diagnosis and even colonscopic removal of the appendix may be technically feasible (8-10), neoplastic lesions, particularly if invasive, should still be completely resected with sufficient margins. In some patients, as in the present case, precise endoscopic definition of the site of origin (cecal or appendiceal), may be difficult (and, to some extent academic) if the appendiceal base (rather than the tip) appears to be the principal area of neoplastic change because complete surgical excision is essential. Indeed, multiple adenomas confined to the body of the appendix without cecal involvement have occurred, but wide excision of the adjacent colon was recommended (15). In malignant appendiceal neoplasms or even in those with a highgrade dysplasia and a high-risk of malignancy, more extensive excision should be performed. Many recommend right hemicolectomy as the treatment of choice for all malignant appendiceal neoplasms, except for small classical carcinoids less than $2 \mathrm{~cm}$ in diameter that are located at the tip of the appendix with a low proliferative index, without angiolymphatic or mesoappendiceal extension (1).

The true risk of appendiceal neoplasia in patients with colon cancer is not known. It has been estimated that the risk of synchronous colon neoplasia is 3\%, with a further $2 \%$ to $3 \%$ risk of metachronous cancer in patients with colorectal cancer. In a recent report from the United Kingdom (7), consecutive patients having a left colectomy or anterior resection had a coincidental appendectomy. Data in this study were also collected from patients having a right hemicolectomy. In patients with colon cancer who had an appendix available for pathological review, more than $4 \%$ had synchronous appendiceal neoplastic lesions. Because the appendiceal mucosa cannot be fully assessed during surveillance colonoscopy, an argument has been made that coincidental appendectomy should be completed to remove the risk of future appendicitis or neoplasia. Further studies are needed to confirm this observation because of its important implications for future surveillance strategies and surgical treatment. 


\section{REFERENCES}

1. O'Donnell ME, Badger SA, Beattie GC, Carson J, Garstin WI. Malignant neoplasms of the appendix. Int J Colorectal Dis 2007;22:1239-48

2. Freeman HJ. Appendiceal carcinoids in Crohn's disease. Can J Gastroenterol 2003;17:43-6.

3. West NE, Wise PE, Herline AJ, Muldoon RL, Chopp WV, Schwartz DA. Carcinoid tumors are 15 times more common in patients with Crohn's disease. Inflamm Bowel Dis 2007;13:1129-34.

4. Winawer SJ, Zauber AG, Fletcher RH, et al; US Multi-Society Task Force on Colorectal Cancer; American Cancer Society. Guidelines for colonoscopy surveillance after polypectomy: A consensus update by the US Multi-Society Task Force on Colorectal Cancer and the American Cancer Society. Gastroenterology 2006;130:1872-85.

5. Rex DK, Kahi CJ, Levin B, et al; American Cancer Society; US Multi-Society Task Force on Colorectal Cancer. Guidelines for colonoscopy surveillance after cancer resection: A consensus update by the American Cancer Society and US Multi-Society Task Force on Colorectal Cancer. Gastroenterology 2006;130:1865-71.

6. Levin B, Lieberman DA, McFarland B, et al; for the American Cancer Society Colorectal Cancer Advisory Group, the MultiSociety Task Force, and the American College of Radiology Colon Cancer Committee. Screening and surveillance for the early detection of colorectal cancer and adenomatous polyps, 2008: A joint guideline from the American Cancer Society, the US
Multi-Society Task Force on Colorectal Cancer, and the American College of Radiology. CA Cancer J Clin 2008;58:130-60.

7. Khan MN, Moran BJ. Four per cent of patients undergoing colorectal cancer surgery may have synchronous appendiceal neoplasia. Dis Colon Rectum 2007;50:1856-9.

8. Wirschafter SK, Kaufman H. Endoscopic appendectomy. Gastrointest Endosc 1976;22:173-4.

9. Gaylord SF. Colonoscopic appendectomy. Gastrointest Endosc 1981;27:203.

10. Vernava AM III, Johnson FE. Colonoscopic appendectomy: Report of a case. Dis Colon Rectum 1991;34:83-4.

11. Freeman HJ. Heterogeneity of colorectal adenomas, the serrated adenoma, and implications for screening and surveillance. World J Gastroenterol 2008;14:3461-3.

12. Rubio CA. Serrated adenomas of the appendix. J Clin Pathol 2004;57:946-9.

13. Yantiss RK, Panczykowski A, Misdraji J, et al. A comprehensive study of nondysplastic and dysplastic serrated polyps of the vermiform appendix. Am J Surg Pathol 2007;31:1742-53.

14. Hu CC, Chang JJ, Chen TC, Yen CL, Chien RN. Colonoscopic feature of primary adenocarcinoma of the appendix. Intern Med 2008;47:255-7.

15. Denoel C, Legrand MJ, Heymans O, Kunsch JM. Isolated adenomatous polyposis of the appendix: Report of a case. Dis Colon Rectum 2001;44:1709-10. 


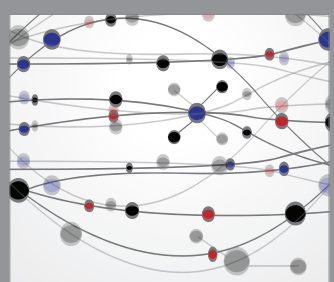

The Scientific World Journal
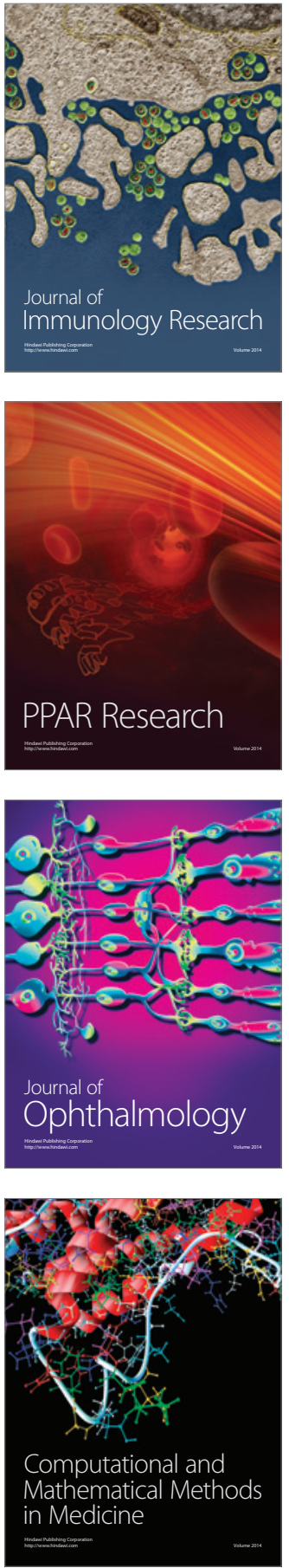

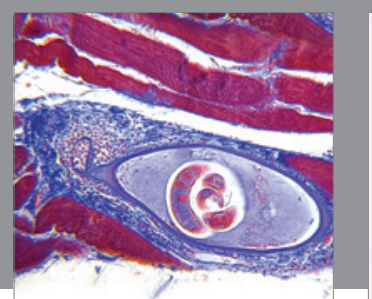

Gastroenterology Research and Practice

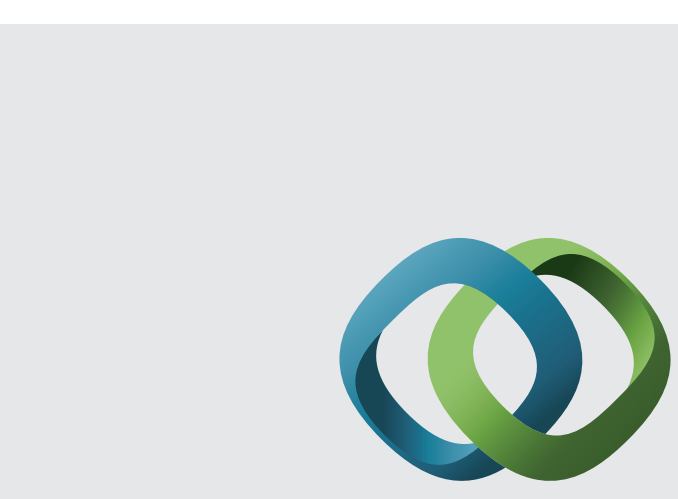

\section{Hindawi}

Submit your manuscripts at

http://www.hindawi.com
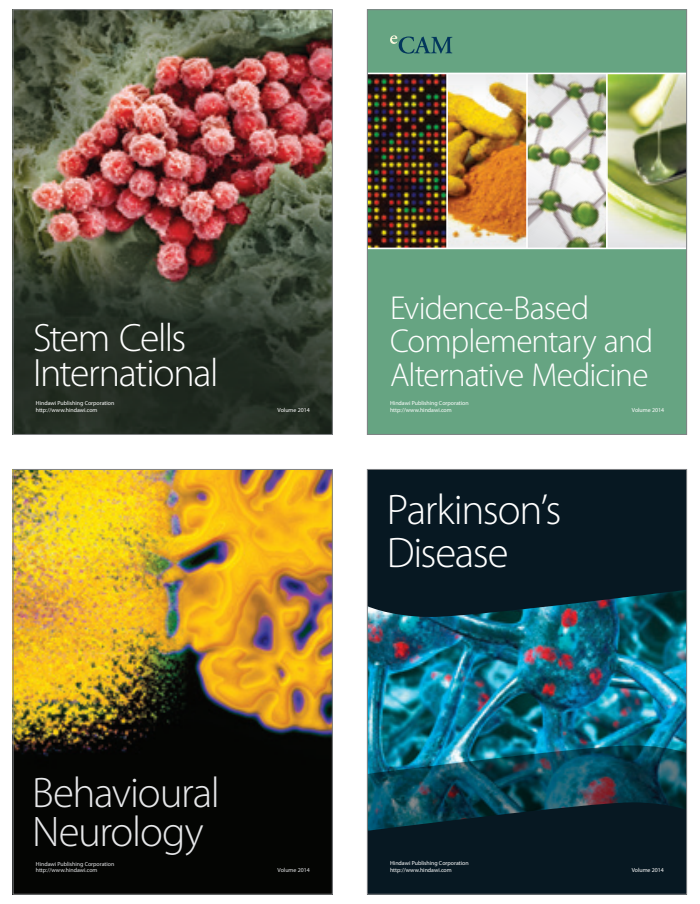
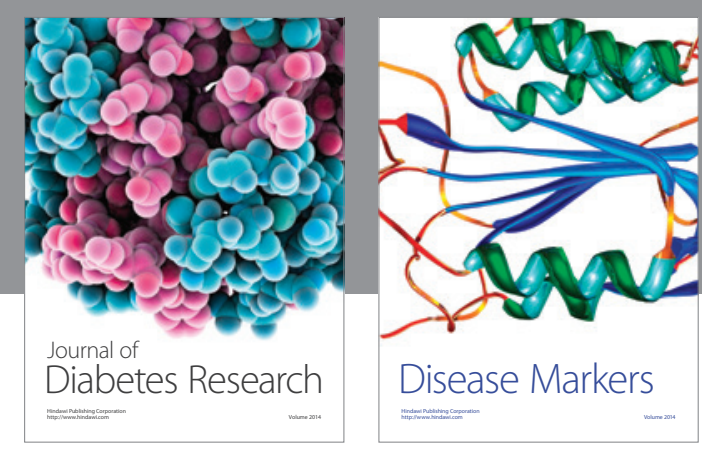

Disease Markers
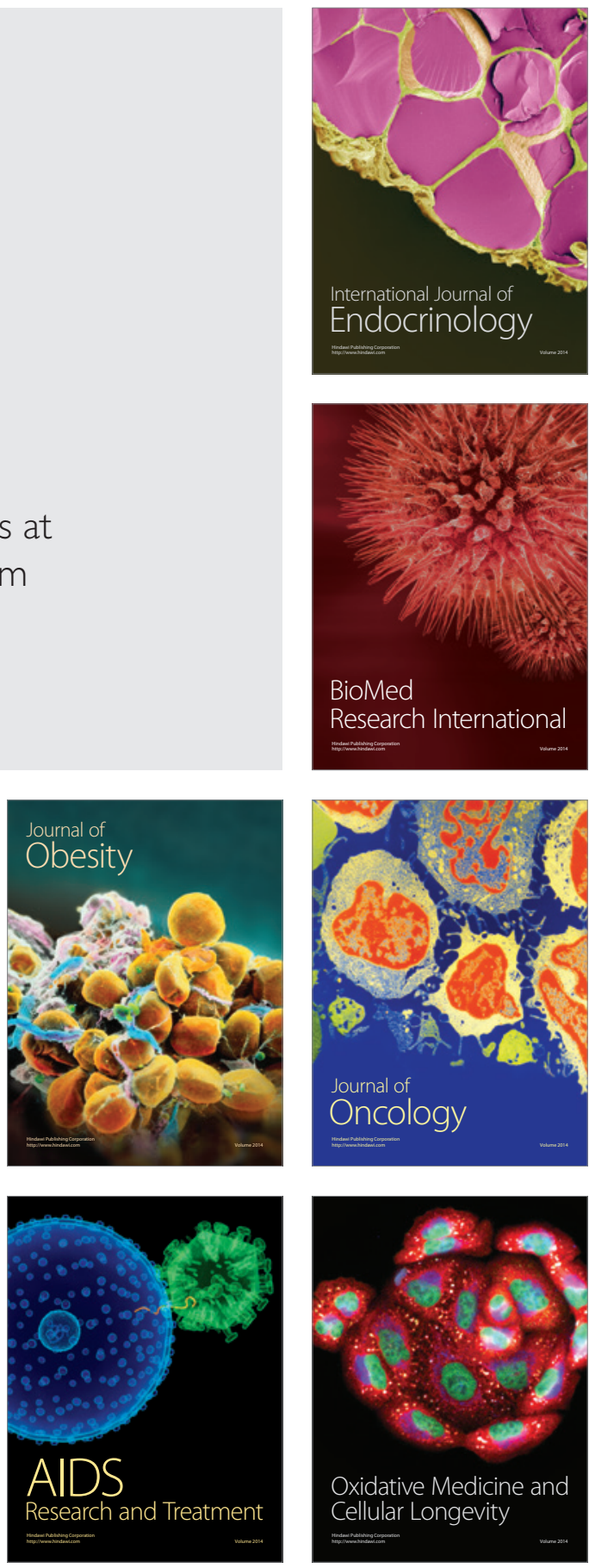